\title{
Intersubjetividade e transindividualidade a partir de Leibniz e Espinosa
}

Vittorio Morfino*

Resumo: Um dos mal-entendidos mais persistentes que cercam a filosofia leibniziana consiste, sem dúvida, em querer ver nela uma forma de espinosismo. Por outro lado, toda oposição que se faz entre Leibniz e Espinosa no plano teórico aparentemente não ultrapassa a visão hegeliana da relação entre os dois filósofos como oposição entre universalidade e individualidade. Pretende-se aqui, diferentemente, confrontar os dois filósofos em relação à questão da individualidade confrontando os seus prolongamentos teóricos do século XX. De um lado, a intersubjetividade husserliana como prolongamento teórico da monadologia; de outro, o conceito simondoniano de transindividualidade que, com Balibar, permite-nos prolongar o pensamento espinosano na contemporaneidade. Tentarse-á marcar toda a distância que separa estes dois sistemas segundo uma abordagem que não se limita a repetir o velho refrão hegeliano.

Palavras-chave: Espinosa, Leibniz, transindividualidade, intersubjetividade.

\section{Monadologia e espinosismo}

Na história dos mal-entendidos a respeito da filosofia leibniziana certamente está, entre os mais curiosos e insistentes, aquele que nela quer ver uma forma de espinosismo; uma incompreensão em duplo sentido, pois, para poder afirmar-se, opera uma redução da complexidade tanto de Leibniz quanto de Espinosa. Leibniz já se expressava de maneira inequívoca nos últimos anos de sua vida, em resposta a uma carta de Bourguet:

Eu não sei, senhor, como podeis tirar daí qualquer espinosismo; é passar um tanto rápido às conclusões. Ao contrário, é justamente graças a essas mônadas que o espinosismo é destruído, porque existem tantas substâncias verdadeiras, e, por assim dizer, espelhos vivos do universo sempre subsistentes, ou universos concentrados, quantas mônadas existem, enquanto que, segundo Espinosa, não existe nada além de uma só substância. Ele teria razão caso não

* Professor na Universitá degli studi di Milano - Bicocca

Tradução de Herivelto Pereira de Souza 
existissem mônadas; então tudo, fora de Deus, seria passageiro e se esvairia como simples acidentes ou modificações, uma vez que não existiria a base das substâncias nas coisas, a qual consiste na existência das mônadas.(Leibniz 11, p.575)

Na resposta de Leibniz está presente o forte componente ideológico sublinhado por Friedmann, que afirma que "na galeria de doutrina mobiliada pela propaganda leibniziana dos últimos anos, o espinosismo joga cada vez mais o papel do maligno, que a harmonia preestabelecida vem exorcizar" (Friedmann 5, p.163), uma monadologia que se ergue como último baluarte cristão contra o ateísmo; todavia, a importância da resposta não pode ser limitada a este aspecto: ela apresenta um ponto teórico fundamental de afastamento progressivo das duas filosofias, aquele que Balibar, usando uma bela expressão de Foucault, definiu como o "ponto de heresia" (Balibar 1, p.8).

Em um plano estritamente metafísico, foi Friedrich Heinrich Jacobi a colocar em relevo a oposição entre os dois sistemas, em um apêndice à segunda edição das suas célebres Cartas ao Sr. Moses Mendelssohn sobre a teoria de Espinosa (apêndice este feito para corrigir a insistência, na primeira edição, sobre a identidade substancial dos dois sistemas): a presença, em Leibniz, do conceito de forma substancial, de um principium individuationis, torna os dois sistemas não apenas diferentes, mas opostos. (Jacobi 10, p.114; trad. p.252) Esta oposição foi canonizada e ao mesmo tempo dialetizada por Hegel na célebre nota ao primeiro capítulo da terceira seção da Teoria da Essência (Hegel 7, p.376-378; trad. p.604-606): aqui a oposição Espinosa-Leibniz perde os caracteres contingentes do horizonte histórico que a viu surgir, para se tornar um jogo categorial que a mente de Deus conduz na eternidade do elemento lógico. Nessa oposição, em sua existência histórica, exprime-se a dialética de duas unilateralidades que deverão ser superadas pelo desdobrar-se do processo: se, de fato, na filosofia espinosana, o sujeito naufraga na totalidade da substância, na filosofia leibniziana o sujeito pode ser colocado apenas se toma como própria a lei das suas relações com as outras mônadas, isto é, se a sua atividade é entendida somente em sentido relativo. Olhando bem, Hegel repete a opinião leibniziana ${ }^{1}$ colocando a dialética das duas unilateralidades a serviço de sua própria filosofia: a substância sem sujeito de um lado e os sujeitos sem totalidade imanente de outro, preparando o caminho para aquele fazer-se sujeito da substância que é o núcleo central de seu pensamento.

Em um plano teorético, além dos contornos do esboço hegeliano nada houve além de mera repetição. ${ }^{2}$ Todavia, se colocada em um plano puramente metafísico, a oposição parece ser estéril: a eterna repetição da dialética Um-Muitos, que habita a tradição ocidental desde o Parmênides de Platão, refratar-se-ia na díade Espinosa-Leibniz através da lente metafísica da substância. Uma ou muitas substâncias: eis o dilema. Porém, se se renuncia a um olhar panorâmico sobre a história do pensamento e se aproxima a terminologia dos dois autores, torna-se imediatamente claro que todo esquema opositivo simplista resulta inadequado e redutivo ${ }^{3}$, como demonstra aquele extraordinário protocolo de leitura que é o manuscrito leibniziano Ad "Ethicam", cujo aspecto proeminente consiste precisamente na impossibilidade de Leibniz em traduzir a terminologia metafísica espinosana dentro de sua própria filosofia.(Cf. Morfino 15) Buscar-se-á, então, desativar a questão através de um duplo movimento: de um lado, situar a oposição não em nível metafísico (unicidade da substância contra pluralidade das mônadas) mas sobre o plano do finito e de suas relações internas (mônadas contra modos); e de outro lado, desvinculá-la do plano meramente historiográfico para avaliar sua potência em termos de história dos efeitos, projetando-a sobre um terreno que, em última instância, é teorético.

\section{Intersubjetividade transcendental}

Se há um autor na filosofia do século XX que restitui vigor ao projeto leibniziano de uma monadologia, ele é sem dúvida alguma Edmund Husserl. Na medida em que se avança na leitura das Meditações Cartesianas, a figura de Leibniz parece deslocar do centro da cena teórica fundamental a de Descartes, culminando na quinta meditação, dedicada à intersubjetividade, quando Husserl propõe, apertis verbis, a sua própria teoria como uma monadologia.

Percorramos brevemente as passagens fundamentais desse caminho. O primeiro e bem conhecido movimento teórico husserliano consiste na repetição da dúvida universal cartesiana que conduz a um ego puro (ou "ego reduzido"), pura interioridade dotada do caráter de evidência apodítica. Deste modo, o ego cogito resulta no "solo judicativo último e apoditicamente certo sobre o qual toda filosofia radical é fundada" (Husserl 9, p.58; trad. 
p.52); diante do mundo, assim como dos outros, eu não sou mais do que uma pretensão de existência, um Seinsanspruch, isto é, perdem-se "as inteiras formações da socialidade e da cultura [die ganzen Gebilde der Sozialität und der Kultur]" (Husserl 9, p.58-59; trad. it. p. 52) em sua crença existencial, Seinsglauben. Esta epoché, esta "redução fenomenológicoexistencial" é, como dito, a repetição de um movimento cartesiano e, no entanto, ao mesmo tempo, uma tentativa de atingir uma radicalidade mais profunda: a colocação do mundo entre parênteses enquanto método, graças ao qual eu tomo a mim mesmo como eu puro, constitui, de fato, uma tomada de distância da identificação cartesiana entre cogito e substantia, na qual Husserl vê uma espécie de reificação do eu puro.

Esse primeiro movimento, porém, graças ao qual eu entro em contato com a evidência do cogito, não é um fim em si mesmo. Ele me permite ter acesso à multiplicidade das experiências de si do viver transcendental:

a mera identidade do "eu sou" não é o conteúdo absolutamente indubitável da experiência transcendental de si, antes, estende-se através de todos os dados particulares da real e possível experiência de si [...] uma universal e apodítica estrutura de experiência do eu. (Husserl 9, p.67; trad. it. p.60)

Assim, a fenomenologia transcendental resulta uma ciência absolutamente subjetiva, enquanto o objeto, no seu ser, é independente da decisão acerca da existência ou da não existência do mundo. Porém, segundo Husserl, apenas em aparência estamos diante de um solipsismo transcendental, uma vez que "sua execução conseqüente, conforme seu próprio sentido, conduz a uma fenomenologia da intersubjetividade transcendental" (Husserl 9, p.69; trad. it. p.62): no fundo, o solipsismo seria apenas um estágio inferior, uma consideração metodológica necessária para poder colocar em funcionamento a problemática da intersubjetividade transcendental. Vejamos como.

O campo de trabalho do ego reduzido compreende todo o mundo e a ciência objetiva, um ego que permanece idêntico nas multíplices cogitationes, "a vida corrente da consciência [das strömende Bewusstseinleben] na qual vive o eu idêntico" (Husserl 9, p.70; trad. it. p.62): a expressão mais correta da evidência apodítica é, portanto, segundo Husserl, ego cogito + cogitatum na dupla direção noética e noemática. Este fluxo de
Erlebnisse [vivências] na consciência não é dado sem conexão, mas como síntese:

na reflexão pura vejo que este cubo é dado de maneira contínua como unidade objetiva em uma variável e multiforme multiplicidade que determina modos fenomênicos que lhe fazem parte [in einer vielgestaltigen wandelbaren Mannigfaltigkeit bestimmt zugehöriger Erscheinungsweise]. (Husserl 9, p.77; trad. it. p.69)

É a síntese da consciência que estabelece a unidade do objeto na pluralidade das suas manifestações: "a inteira vida da consciência [...] é unificada sinteticamente" (Husserl 9, p.80; trad. it. p.72). A tarefa do fenomenólogo não é descrever de maneira ingênua o objeto, mas os modos pelos quais a consciência o constitui enquanto tal:

apenas deste modo o fenomenólogo pode tornar compreensível para si como na imanência da vida da consciência, e em quais modos constituídos de consciência estes fluxos ininterruptos de consciência, assim como as unidades objetivas estáveis e permanentes, podem tornar-se conscientes, e em particular, como vem a efetuar-se essa maravilhosa realização da constituição dos objetos idênticos para cada categoria de objeto. (Husserl 9, p.85; trad. it. p.77)

No fluxo heraclitiano da consciência cada objeto designa uma estrutura de regras do eu transcendental.

Até aqui, sumariamente, as três primeiras meditações, as quais vão na direção de uma transcendentalização do cogito cartesiano. Com a quarta se abre o percurso, por assim dizer, leibniziano. De fato, o ego não é um pólo de identidade vazio, pois "para cada ato que emana de si [ele] adquire um novo sentido objetivo, uma nova propriedade durável [eine neue bleibende Eigenheit]" (Husserl 9, p.100; trad. it. p.92). E mais:

enquanto o eu, por sua própria gênese ativa, constitui-se como substrato idêntico de duráveis propriedades-do-eu [identisches Substrat bleibender Ich-Eigenheiten], constitui-se também ulteriormente como eu pessoal estável e permanente - naquele 
sentido mais amplo, que permite também se falar em pessoas infra-humanas (Husserl 9, p.101; trad. it. p.93).

O eu se constitui como estilo permanente, como caráter pessoal. Mas o eu como pólo idêntico e como substrato de habitualidade é ainda diferente do eu na sua plena concretude; a este, Husserl chama de mônada, o ego enquanto possui "um mundoambiente contínuo" [eine fortwährend Umwelt]" (Cf. Husserl 9, p.102; trad. it. p.94) ${ }^{4}$.

Neste ponto Husserl se coloca a pergunta fundamental para o seu projeto: como sair do "domínio da consciência [Bewusstseinsbereich]" (Husserl 9, p.116; trad. it. p.106), da "ilha da consciência [Bewusstseinsinsel]"(Ibidem; trad. it. p.107)? Ou seja, como é possível que a evidência tenha mais do que o caráter de dado da consciência? É aqui, precisamente, que se abre o problema da intersubjetividade: não tem sentido colocar, como fez Descartes, o universo do ser como externo ao universo da consciência estabelecendo uma lei fixa de correspondência entre os dois (correspondência que necessita de uma garantia divina); é suficiente que em mim sejam constituídos transcendentalmente outros ego e um mundo objetivo. Trata-se, aqui, de sair de um solipsismo transcendental, da imanência da consciência, para mover-se em direção à transcendência do outro.

Husserl aborda a questão analisando como se forma em mim o sentido do alter ego. Trata-se, em primeiro lugar, de operar uma redução metodológica da esfera de pertencimento, isto é, de excluir “do campo temático tudo aquilo que agora é questionável", isto é, de "[fazer] abstração de todos os produtos constitutivos da intencionalidade orientada mediata ou imediatamente à subjetividade estrangeira [fremde Subjektivität]" (Husserl 9, p.124; trad. it. p.116); Husserl considera, porém, que:

uma tal abstração não é radical, um tal ser-sozinho não muda nada no sentido de mundo natural do ser-experienciável-para-cada-um [Für-jedermann-erfahrbahr], o qual também adere ao eu entendido de maneira natural, e que não seria perdido mesmo se uma peste universal me deixasse sozinho. (Husserl 9, p.125; trad. it. p.116)

Assim, naquilo que me é próprio enquanto mônada, "[que existe] puramente em mim mesmo e para mim mesmo, em clausura do que me é próprio [in abgeschlossener
Eigenheit]" (Husserl 9, p.125; trad. it. p.117), há a intencionalidade do estrangeiro: “constitui-se o novo sentido do ser que ultrapassa meu eu monádico no que é próprio de si mesmo, e se constitui um ego não como eu mesmo, mas como um que se espelha no meu eu próprio, na minha mônada [sondern als sich in meinem eigenen Ich, meiner Monade spiegelndes]" (Ibidem). Este segundo ego não está "presente", não nos é dado "autenticamente", mas é constituído como alter ego. A questão acerca da possibilidade de intencionar o estrangeiro permanece, porém, de difícil solução: "Deve haver aqui - escreve Husserl - uma certa mediaticidade da intencionalidade que procede a partir da camada inferior do mundo primordial [primordinale Welt], colocada sempre como fundamental" (Husserl 9, p.139; trad. it. p.129). Esta mediação deveria tornar representável o Mit-da sem que se possa sequer mostrar-se como um Selbst-da. Tratase do ato de tornar co-presente, de uma espécie de apresentação, de tipo diferente com respeito àquela presente na experiência externa, segundo a qual, por exemplo, o lado visto de um objeto me apresenta aquele posterior, escondido. A apresentação do outro é de tipo diferente: "ego e alter ego são dados sempre e necessariamente em emparelhamento originário [ursprüngliche Paarung]" (Husserl 9, p.142; trad. it. p.132), emparelhamento que é um presentar-se configurante como par, grupo, multidão, uma síntese passiva de associação segundo a qual, pelo fato de que eu sou um corpo orgânico, se aparece na minha esfera primordial um corpo semelhante ao meu, "[um corpo] que deve entrar em emparelhamento fenomenal [phänomenale Paarung] com o meu [corpo]" (Husserl 9, p.143; trad. it. p.133) ${ }^{5}$, aquele corpo assume sentido de corpo orgânico através de uma transferência de sentido.

A questão diz respeito, agora, a como esse sentido pode ter valor de ser. Segundo Husserl,

a apresentação [Appräsentation] que me dá o outro na sua inatingível originalidade é entrelaçada a uma presentação [Präsentation] original (de seu corpo como parte da natureza dada a mim singularmente [seines Körpers als Stück meiner eigenheitlich gegebenen Natur]). Mas neste entrelaçamento [Verflechtung] o corpo-orgânico estrangeiro e o eu estrangeiro que o governa são dados no modo de uma experiência transcendente unitária. (Husserl 9, p.143-144; trad. it. p.134) 
Essa experiência do estrangeiro pode ser verificada "mediante novas apresentações decorrentes em concordância sintética" (Husserl 9, p.144; trad. it. p.134). "Fica claro, com isso, - continua Husserl - que na modificação analógica é apresentado tudo aquilo que pertence à concretude deste eu, em primeiro lugar como seu mundo primordial e depois como ego inteiramente concreto" (Husserl 9, p.144; trad. it. p.135). Assim, por apresentação, constitui-se na minha mônada uma outra mônada que, no entanto, não posso nunca apreender originaliter, e que, por isso, tem o caráter da transcendência.

Essa experiência do estrangeiro funda a objetividade do mundo e a comunidade das mônadas, isto é, a sua temporalidade comum:

[...] estabelece em sua complexa estrutura uma ligação semelhante, mediada através de presentificações [Vergegenwärtigung], entre a experiência de si (enquanto pura manifestação de si passiva e original), que prossegue em vivacidade ininterrupta, do eu concreto, portanto sua esfera primordial, e a esfera do estrangeiro nela presentificada [vergegenwärtigten]. Ela estabelece tal ligação mediante uma síntese identificadora do corpo-orgânico estrangeiro primordialmente dado consigo mesmo, só que apresentado em outro modo fenomênico, e, a partir daí, estende-se através da síntese identificadora da mesma natureza dada e verificada ao mesmo tempo primordial (em pura originalidade sensória) e apresentativamente. Dessa forma, é originariamente fundada a coexistência do meu eu (e do meu ego concreto, em geral) com o eu estrangeiro, da minha vida intencional com a sua, das minhas realidades com as suas; em uma palavra, [é fundada] uma forma temporal comum [eine gemeinsame Zeitform], onde cada temporalidade primordial [primordinale Zeitlichkeit] adquire por si mesma o mero significado de um original e subjetivo-individual modo fenomênico da temporalidade objetiva. Vê-se, aqui, como a comunidade temporal [zeitliche Gemeinschaft] das mônadas, mutuamente referidas de maneira constitutiva, é indissociável, porque essencialmente relacionada à constituição do mundo e do tempo do mundo [Weltzeit]. (Husserl 9, p.156; trad. it. p.146)

A contemporaneidade das mônadas, o seu ser-ao-mesmo-tempo (Husserl
9, p.166; trad. it. p.156), funda a unicidade da comunidade monádica, a unicidade e a objetividade do mundo, a unicidade do espaço e a unicidade da temporalidade real.

Essa comunidade tem dois graus de formação: em um grau mais baixo, a outra mônada é constituída em mim como estrangeira, as outras mônadas são realiter separadas da minha, ou seja, não há liame real entre os momentos de consciência delas e os meus; em um grau mais elevado, se eu dirijo minha compreensão em direção ao outro ser humano, descubro que, como seu corpo orgânico se encontra no meu campo perceptivo, também o meu se encontra no dele. Esta reciprocidade funda a comunidade monádica, a intersubjetividade transcendental que "traz consigo, necessariamente, o mesmo mundo objetivo constituído" (Husserl 9, p.158; trad. it. p.148). De maneira extremamente sintética, poderíamos dizer que o primeiro nível é cartesiano, enquanto o segundo é leibniziano. Como escreve o próprio Husserl:

Assim, à constituição do mundo objetivo pertence essencialmente uma harmonia das mônadas, mais precisamente, uma tal constituição harmônica particular das mônadas e, conforme a isso, também uma harmonia na gênese singular que prossegue. (Husserl 9, p.138; trad. it. p.128; itálicos meus)

A constituição da intersubjetividade transcendental necessita, assim, do conceito de mônada como espelho sintético de um mundo-ambiente e do conceito de comunidade monádica como reciprocidade dos espelhamentos, sincronia dos mundos. Esta harmonia não teria, porém, uma estrutura metafísica, tampouco as mônadas seriam invenções ou hipóteses metafísicas: a saída do solipsismo não seria tornada possível, de fato, como quis sublinhar o próprio Husserl, "por uma metafísica inconfessa, por uma retomada oculta de tradições lebnizianas" (Husserl 9, p.174; trad. it. p.164).

\section{Intersubjetividade metafísica}

A questão fundamental da teoria da intersubjetividade transcendental (que é também a mesma questão sobre o valor da evidência vinda de fora da cercadura da consciência) diz respeito a este conceito não metafísico de mônada e de harmonia 
que Husserl coloca como fundamento de sua teoria. O que, exatamente, Husserl entende por conceito não metafísico de mônada e de harmonia? Parece-me que, para ele, a teoria da intersubjetividade transcendental não necessita de alguns pressupostos metafísicos leibnizianos que elenco sinteticamente a seguir, percorrendo os parágrafos da Monadologia:

1) a substancialidade das mônadas;

2) que as mônadas só poderiam "começar por criação e acabar por aniquilação" (Leibniz 12, §6, p.607; trad. it., p.453);

3) que "como todo o estado presente de uma substância simples é uma continuação natural do seu estado passado, assim também o presente está prenhe do futuro" (Leibniz 12, §22, p.610; trad. it., p.456);

4) que "a razão última das coisas deve encontrar-se numa substância necessária, na qual o pormenor das modificações só esteja eminentemente, como na origem. É o que chamamos Deus" (Leibniz 12, §38, p.613; trad. it., p.458-459);

5) que o intelecto de Deus seja o fundamento ontológico da possibilidade (Leibniz 12, §43, p.614; trad. it., p.459);

6) que tenha lugar uma influência meramente ideal "de uma Mônada sobre outra, influência que só pode exercer-se com a intervenção de Deus" (Leibniz 12, §51, p.615; trad. it., p.460);

7) que Deus tenha escolhido, entre uma infinidade de universos possíveis, aquele com o maior grau de perfeição (Leibniz 12, §53-55, p.615-16; trad. it., p.461);

8) que "a alma [siga] as próprias leis, e o corpo também as suas, e ambos se [ajustem] devido à harmonia preestabelecida entre todas as substâncias” (Leibniz 12, §78, p.620; trad. it., p.465);

9) que haja uma harmonia “entre o reino Físico da Natureza e o reino Moral da Graça” (Leibniz 12, §87, p.622; trad. it., p.467).

Aquilo que Husserl rechaça é o conceito de harmonia dominada pelo par especular da onto-teologia: substância finita - substância infinita, mônada - Deus.

Trata-se, então, de compreender em que sentido a teoria da intersubjetividade transcendental husserliana possa ser dita uma monadologia, mesmo com a recusa desse par conceitual. Renato Cristin, na introdução à edição italiana das Meditações, dá ênfase ao "papel relacional das mônadas" (Cristin 3, p.XV) abaixo, uma reflexão um tanto pouco perspícua sobre a velocidade admitida pelo conceito de mônada: "Como um multiplicador de velocidade, a mônada consente que se passe de uma situação à outra, do eu ao Outro, com uma facilidade maior comparada à lentidão do cogito cartesiano" (Cristin 3, p.XV). Convém, então, deter-se sobre a primeira indicação: a imediata relacionalidade da mônada como aspecto central da retomada husserliana de Leibniz. Esta imediata relacionalidade da mônada está bem expressa nesta passagem da Monadologia, na qual retorna o tema, caro a Leibniz, da cidade observada de diferentes perspectivas:

[...] esta acomodação de todas as coisas criadas a cada uma e de cada uma a todas as outras faz cada substância simples ter relações que exprimem todas as outras e ser, portanto, um espelho vivo e perpétuo do universo. [...] E, assim como a mesma cidade parece outra e se multiplica perspectivamente sendo observada de diversos lados, o mesmo sucede quando, pela infinita quantidade das substâncias simples, parece haver outros tantos universos diferentes, que, no entanto, são apenas as perspectivas de um só, segundo os diferentes pontos de vista de cada Mônada. (Leibniz 12, §56-57, p.616; trad. it., p.461).

O mundo, a unidade do mundo na sua dimensão espaço-temporal, nada é além de um fenômeno fundado na inter-relação das mônadas. A intersubjetividade precede e funda a objetividade do mundo.

Todavia, Husserl nos diz que a harmonia entre as mônadas é uma harmonia não metafísica. Nesta afirmação, aparentemente sem problemas, na realidade se esconde o verdadeiro e próprio malogro da intersubjetividade husserliana. O que significa harmonia não metafísica? Releiamos a passagem-chave de Husserl:

à constituição do mundo objetivo pertence essencialmente uma harmonia das mônadas, mais precisamente, uma tal constituição harmônica particular das mônadas e, conforme a isso, também 
uma harmonia na gênese singular que prossegue.

Em que consiste esta harmonia das mônadas que funda o mundo objetivo? Em Leibniz, a resposta é conhecida: “Ora, sendo esta substância [necessária] razão suficiente de todo aquele pormenor que, por sua vez, está [entrelaçado] em toda parte, há um só Deus, e esse Deus é suficiente" (Leibniz 12, §39, p.613; trad. it., p.459). A unidade de Deus funda a unidade do mundo, Deus antecipa e fecha os jogos relacionais das mônadas no cálculo que origina o mundo. Em Husserl, não é assim: “Se [...] no cosmo leibniziano - escreve Cristin - a atividade das mônadas era preordenada sobre a base da harmonia universal, em Husserl o conceito de mônada é carregado de uma valência de autonomia, de espontaneidade, de capacidade de operar no mundo" (Cristin 3, p.XV).

Em um plano teórico, essa resposta é completamente insatisfatória, ou seja, não responde à questão fundamental sobre a harmonia das mônadas, que é aquilo que torna possível a intersubjetividade transcendental e funda o mundo objetivo. Husserl rechaça a solução cartesiana da veracitas divina que coloca fora de jogo a hipótese do gênio maligno, mas também a harmonia preestabelecida leibniziana que sincroniza o tempo de todas as mônadas, fazendo do tempo interno delas o espelho, diversamente situado, da história do mundo. A resposta propriamente husserliana reside na idéia de comunidade monádica como contemporaneidade essencial:

O ser em conjunto das mônadas, o seu mero ser-ao-mesmo-tempo [ihr bloßes Zugleichsein], significa, por necessidade de essência, uma simultaneidade temporal [wesensnotwendig Zeitlichzugleichsein] e, então, também a sua realização temporal sob a forma de temporalidade real [Verzeitlicht-sein in der Form realer Zeitlichkeit] (Husserl 9, p.166; trad. it., p.156).

Mas este ser-ao-mesmo-tempo não pode nunca ser realmente percebido, dado que uma mônada não pode nunca atingir originaliter o fluxo vital de uma outra mônada. A temporalidade do alter ego é sempre apenas apresentada, nunca dada diretamente. Nesse ser-ao-mesmo-tempo das mônadas, nessa harmonia sem metafísica, esconde-se nada menos que um Deus, seja ele aquele transcendente de Berkeley ou aquele imanente do espírito objetivo hegeliano: a contemporaneidade essencial é o nome husserliano de Deus. A intersubjetividade só pode ser metafísica: uma vez que se repita o movimento agostiniano da busca pela verdade in interiore homine, movimento que Husserl reivindica na conclusão das suas Meditações (Husserl 9, p.183; trad. it., p.172), apenas um Deus pode nos permitir de sair da interioridade e de reencontrar o mundo.

\section{Simondon e o transindividual}

Se a intersubjetividade transcendental revela-se no fundo como uma intersubjetividade metafísica, será preciso tentar percorrer uma outra estrada na tentativa de fundar a existência de uma comunidade e de um mundo objetivo sem recorrer a um Deus (mesmo que seu papel seja reduzido a mero garante de uma sincronia dos mundos para além do bem e do mal). Proporei, para tanto, um détour que me permita fornecer em termos extremamente sintéticos as coordenadas históricas da emergência do conceito de "transindividual", do qual pretendo servir-me em seguida para sublinhar, em toda a sua força, a alternativa Espinosa/Leibniz.

O termo foi introduzido por Gilbert Simondon em um livro, L'individuation psychique et collective, publicado postumamente em 1989, que constituía a última parte de uma tese de doutorado escrita nos anos 1950, das quais as duas primeiras partes haviam sido publicadas em 1964 com o titulo de L'Individu et sa genèse physico-biologique. O conceito central, como aparece mesmo a um olhar apenas superficial aos dois títulos, é o de individuação, sobre cujos processos Simondon propõe-se fixar sua atenção, em oposição a uma tradição que concedeu um privilégio ontológico ao indivíduo já constituído. Tanto a tradição substancialista, quanto aquela hilomórfica, de fato,

supõem que existe um princípio de individuação anterior à individuação ela mesma, suscetível de explicá-la, de produzi-la, de conduzi-la. A partir do indivíduo constituído e dado, esforça-se em remontar às condições de sua existência.(Simondon 21, p.9)

Trata-se, segundo Simondon, de conhecer o indivíduo através da individuação, mais do que a individuação a partir do indivíduo, em outras palavras, de inverter 
radicalmente a perspectiva a partir da qual se observa o indivíduo, afirmando com força o primado da individuação:

O indivíduo seria, então, entendido como uma realidade relativa, uma certa fase do ser que pressupõe uma realidade pré-individual, e que, mesmo após a individuação, não existe completamente só, porque a individuação não esgota de uma vez por todas os potenciais da realidade pré-individual, e, por outro lado, [porque] o que a individuação faz aparecer não é apenas o indivíduo, mas o par indivíduo-meio. O indivíduo é, assim, relativo em dois sentidos: porque ele não é todo o ser, e porque ele resulta de um estado do ser no qual ele não existia nem como indivíduo, nem como princípio de individuação. (Simondon 21, p.12)

Uma tal inversão de perspectiva foi tornada possível pelo conceito de equilíbrio metastável, que permite de pensar o ser não em termos de substância ou matéria, mas como um sistema teso, supersaturado. Simondon apresenta a individuação física e a individuação no âmbito do vivente como casos de resolução de um sistema metastável, com a diferença de que, enquanto no âmbito físico a individuação advém "de um modo apenas instantâneo, quântico, brusco e definitivo, deixando atrás de si uma dualidade do meio e do indivíduo", "o vivente conserva em si uma atividade de individuação permanente" (Simondon 21, p.16).

É exatamente esse caráter da individuação no âmbito do vivente que permite a Simondon pensar o nível psíquico e o coletivo em termos de individuações sucessivas com respeito à individuação vital. Todavia, a individuação psíquica e a coletiva não devem ser pensadas elas mesmas como sucessivas uma à outra, segundo um modelo de desenvolvimento diacrônico, mas em termos sincrônicos, como um mesmo processo que dá lugar a um interno e a um externo. É neste nível que o conceito de individuação se entrelaça com o tema do transindividual:

As duas individuações, psíquica e coletiva, estão em uma relação de reciprocidade; elas permitem definir uma categoria do transindividual que pretende dar conta da unidade sistemática da individuação interior(psíquica)e daindividuação exterior(coletiva).
O mundo psicossocial do transindividual não é o social bruto, nem o inter-individual; ele pressupõe uma verdadeira operação de individuação a partir de uma realidade pré-individual, associada aos indivíduos e capaz de constituir uma nova problemática dotada de uma sua própria metastabilidade. (Simondon 21, p.19-20)

O transindividual é, então, o nome da complexa trama de relações que constitui ao mesmo tempo a individuação psíquica e aquela coletiva. E, aqui, emerge o terceiro conceito-chave da teoria de Simondon, o conceito de relação, que não é nunca relação entre dois termos preexistentes, mas constituição dos termos colocados em jogo pela relação. Neste sentido, trata-se, segundo Simondon, de delinear um novo método que esteja à altura dos conceitos de individuação e de transindividual:

O método consiste em não tentar compor a essência de uma realidade em meio a uma relação conceitual entre dois termos extremos preexistentes, e em considerar cada verdadeira relação como tendo classe de ser. A relação é uma modalidade do ser; ela é simultânea com relação aos termos dos quais garante a existência. Uma relação deve ser entendida como relação no ser, relação do ser, maneira de ser e não mera relação entre dois termos que se poderia conhecer adequadamente por meio de conceitos, porque eles teriam uma existência efetivamente prévia e separada. (Simondon 21, p.23-24)

Para resumir, o conceito de transindividual é definido a partir de duas teses filosóficas que traçam uma linha clara de demarcação com respeito à tradição metafísica ocidental:

1) primado do processo de individuação sobre o indivíduo;

2) primado da relação sobre os termos da relação.

Transindividual é, então, o nome do sistema metastável que dá ocasião às individuações psíquica e coletiva, trama de relações que atravessa e constitui os indivíduos e a sociedade, interditando metodologicamente a substancialização daqueles ou desta: “a sociedade - escreve Simondon - não surge realmente da mútua presença de muitos indivíduos, mas tampouco é ela uma realidade substancial que deveria ser superposta aos 
seres individuais e concebida como independente deles" (Simondon 21, p.177).

Trata-se, como escreve Balibar, de "uma ambiciosa tentativa de definir uma estrutura das ciências humanas através da crítica [às] doutrinas metafísicas da individualidade, que conduzem ao clássico dualismo interno e externo, ao conhecimento a priori e a posteriori, ao 'psicologismo' e ao 'sociologismo"”. Tais doutrinas, continua Balibar, "têm sempre subordinado a compreensão da individuação (ontogênese) à definição do indivíduo entendido como forma (idealmente) imutável, [enquanto] a física e a biologia modernas (incluídas algumas disciplinas como o estudo do desenvolvimento das estruturas cristalinas e a biologia dos processos cognitivos, nos quais a adaptação à mudança ambiental requer a emergência de novas estruturas) fornecem instrumentos decisivos para projetar um novo conceito geral de ontogênese, mostrando que as formas permanentes (que reduzem a energia potencial ao mínimo) são menos importantes nos processos naturais com respeito aos equilíbrios metastáveis (que requerem um aumento do potencial de energia que deve ser preservado geralmente na polaridade entre indivíduo e ambiente)" (Balibar 2, p.112-113).

\section{Espinosa e o transindividual}

Trata-se, agora, de se perguntar de que modo o conceito de transindividual faz parte do percurso até aqui proposto. Tal conceito deveria constituir o prolongamento contemporâneo da teoria espinosana, assim como a teoria husserliana da intersubjetividade nos forneceu o prolongamento, no século XX, da monadologia leibniziana. A conexão Espinosa-Simondon não é, de fato, imediata: se se quisesse conduzir um trabalho de escavação acerca das fontes filosóficas de Simondon, creio que se encontraria o bergsonismo e a fenomenologia de Merleau-Ponty. O espinosismo não apenas não está presente como fonte influente, mas é até mesmo explicitamente liquidado por Simondon como uma posição panteísta, na qual a realidade individual é negada. É, assim, mais uma vez, à história dos efeitos e a um golpe de força teórico que se deve apelar para pensar a concepção do transindividual como prolongamento da filosofia de Espinosa, ou melhor, e mais verossimilmente, para produzir uma reação química entre o texto de Espinosa e o conceito de transindividual. Este golpe de força foi proposto por Étienne
Balibar, no rastro do projeto althusseriano de repensamento da filosofia marxista através do pensamento de Espinosa ${ }^{7}$. Em um ensaio de 1997, com o eloqüente título de Espinosa. From individuality to transindividuality, ele se propõe não tanto a adaptar a teoria de Espinosa às formulações de Simondon, mas a "discutir o limite dentro do qual o próprio Espinosa pode ser considerado um teórico significativo da transindividualidade, ajudandonos assim a conduzir esta noção da sua inicial definição negativa (uma doutrina que não é nem individualista nem holista, assim como não é nem mecanicista nem finalista) a uma noção mais positiva ou construtiva" (Balibar 2, p.113).

Seguindo este projeto, Balibar delineia três níveis através dos quais pode ser sondada, na Ética, "a idéia da individualidade como transindividual, ou como processo transindividual de individuação" (Balibar 2, p.114):

1) a transindividualidade como específico esquema de causalidade;

2) como elemento determinante na construção de sucessivos graus de individualidade;

3) como conceito latente que articula imaginação e razão.

1) Balibar ressalta que no esquema de causalidade espinosano a complexidade não constitui um momento derivado, mas que está presente desde a origem:

A concatenação infinita não toma a forma de séries lineares independentes, ou de genealogias de causas e efeitos (A 'causa' $B$ que 'causa' C que 'causa' etc): ela assume o aspecto de uma rede infinita de modos singulares ou existências, de uma unidade dinâmica de atividades modulantes/moduladas (a ação de B sobre cada A é, por sua vez, modulada por alguns $C$, que são modulados por um D qualquer, etc.). (Balibar 2, p.117)

Isso significa que cada indivíduo é, ao mesmo tempo, ativo e passivo. Ademais, a essência da causalidade seria "a unidade de atividade e passividade" ou, como sugere ainda Balibar, “em termos quase matemáticos [...] o 'diferencial' entre atividade e passividade", uma unidade que "define o conatus individual singular e o relaciona a uma infinita multiplicidade de outros indivíduos" (Balibar 2, p.119). A transindividualidade, 
aqui, consistiria então no infinitus nexus causarum, naquela ordem por conexão da qual fala a proposição 7, da segunda parte da Ética.

2) Esse nível de complexidade, definido por Balibar de primeiro grau, que estabelece uma equivalência entre o conceito de existência atual de um indivíduo e a pluralidade de relações entre indivíduos diferentes (assim, a impossibilidade de inserir o indivíduo dentro de uma cadeia causal pensada segundo um modelo simples e serial), encontra em Espinosa um aprofundamento através da introdução de um segundo grau de complexidade (justamente nas proposições que se seguem imediatamente à Ética II, 7):

segundo este conceito, o indivíduo é representado como um determinado nível de integração, na medida em que incorpora outros indivíduos (nível de integral 'mais baixo') e a si mesmo em formas ou níveis de integração mais altos (Balibar 2, p.119).

Uma representação do segundo grau de complexidade desse tipo comporta, segundo Balibar, um risco, que consiste no pensar a natureza como hierarquia de formas, ordens de inclusão dos indivíduos uns nos outros, segundo um modelo que seria, em última instância, estático (o ponto de vista, em termos espinosanos, da natura naturata). Ele deve ser entendido, no entanto, dinamicamente (isto é, segundo o ponto de vista da natura naturans), pensando que os indivíduos, como formas dadas com uma estabilidade e identidade, são na realidade o efeito "de uma contínua regeneração das partes constituintes do indivíduo, isto é, [de] um 'fluxo' em direção ao interno e ao externo" (Balibar 2, p.122):

A idéia de Espinosa é simples, mas audaz: aquilo que muda são partes do indivíduo em questão, 'regeneração' significa que um dado indivíduo (chamemo-lo 'Eu') abandona continuamente parte(s) de si, enquanto ao mesmo tempo continuamente incorpora parte(s) de outros (chamemo-los 'esses'), mesmo que esta substituição deixe uma certa 'proporção' (ou essência) invariada. [...] Quanto mais um indivíduo é complexo, tanto mais relações empreenderá com o mundo externo; isto é, quanto mais intensamente trocar as próprias 'partes' com outros indivíduos (semelhantes ou diferentes), tanto mais estas trocas se tornarão necessárias para a preservação de sua existência. (Balibar 2, p.122-126)

Isso significa que cada indivíduo existe entre um nível inferior e um nível superior (as partes que o constituem e o ambiente do qual faz parte):

Por essa razão - escreve Balibar - falei de um 'segundo nível de complexidade’ na compreensão da causalidade natural, porque o modelo transindividual do qual nós nos ocupamos não é apenas entendido como uma interação horizontal ou reciprocidade ao mesmo nível, mas também como um processo de interação que, para cada tipo de indivíduo [...], regride ao nível inferior e simultaneamente progride ao nível superior. (Balibar 2, p.127)

Aqui, o sentido da transindividualidade encontrado por Balibar em Espinosa se aproxima do conceito simondoniano segundo o qual o indivíduo é uma realidade relativa, efeito de um processo de individuação que, de um lado, não exaure o potencial do pré-individual, e de outro, não dá lugar ao individuo isolado, mas ao par indivíduoambiente.

3) Esse segundo grau de complexidade abre espaço ao tratamento do mundo humano e especificamente ao conceito de transindividual como mediação entre imaginação e razão. Balibar mostra, em primeiro lugar, como tanto a estrutura da imaginação quanto aquela da razão são essencialmente transindividuais. Sobre a imaginação Balibar escreve:

pode-se sugerir que 1) a teoria da imaginação de Espinosa não é uma teoria sobre faculdades humanas (individuais ou genéricas, tais como a memória, a percepção, a vontade, etc.), mas sim da estrutura na qual os indivíduos 'eles mesmos' são constituídos primariamente (e que inclui autoconsciência, reconhecimento de si, auto-afirmação); e 2) que essa estrutura é originariamente relacional ou transindividual: isso não apenas nos coloca diante de 
uma imagem da consciência na qual cada relação que 'eu' posso ter 'comigo mesmo' é mediada pelo Outro (mais exatamente por uma imagem do Outro), mas mostra também que a vida da imaginação é um processo circular de 'identificações' sucessivas, no qual eu identifico o Outro a partir de mim mesmo, e eu mesmo a partir do outro (Balibar 2, p.132).

Passando a analisar o conceito espinosano de razão, Balibar nota como esta é

apresentada não como uma faculdade (muito menos uma inspiração divina ou uma essência transcendente), mas como uma estrutura ou um sistema de implicações recíprocas nas quais, para cada indivíduo, o conatus, para preservar a própria existência, comporta o conhecimento do próprio bem [...] e a instituição necessária de um commercium com outros homens(Balibar 2, p.135).

Dada a constituição relacional da imaginação e da razão, Balibar propõe considerar a transindividualidade não como um modelo rígido (ou como dois modelos contrapostos), mas como um processo no qual as relações entre os indivíduos "são consideradas na transição da imaginação à razão, isto é, de um poder de agir menor a um maior" (Balibar 2, p.139). Este terceiro nível de leitura do pensamento espinosano através do conceito de transindividual mostra, então, como "um novo tipo de conhecimento [é], por sua verdadeira natureza, um novo tipo de comunidade" (Balibar 2, p.139) ${ }^{8}$.

\section{Mônada e modo}

Uma vez mostrado o contexto de emergência do conceito de transindividual e a ocasião do seu encontro, através de Balibar, com o pensamento espinosano, é possível tentar enfrentar a questão da alternativa Espinosa/Leibniz lida através dos dois modelos teóricos da intersubjetividade e da transindividualidade, e assinalar, de maneira forte, a distância que os separa. Certamente poderia, ao contrário, ser operada - e o foi muitas vezes na história das interpretações - uma leitura de cunho individualista, monadológico, por assim dizer, dos modos. ${ }^{9}$ Uma vez recusada uma interpretação acosmista à la Hegel, poder-se-ia sentir-se tentado a pensar o modo espinosano como um indivíduo que preexiste e que funda as relações. Em particular, a essência do ser humano seria definida pela díade mente-corpo, cujas propriedades fundamentais seriam o desejo, a alegria e a tristeza. O modo, como a mônada, teria então uma essência que precede a existência, que constituiria o fundamento do jogo relacional. Claro, em Espinosa, como em Husserl, não haveria harmonia preestabelecida, o jogo relacional seria aberto, mas em todo caso entre indivíduos que precedem logicamente a relação. Neste horizonte teórico, as paixões nada seriam além de variações possíveis de uma essência. Argumento apenas aparentemente contrário, mas na realidade favorável a uma interpretação deste tipo, é a ênfase colocada por alguns intérpretes franceses (Matheron, entre outros (cf. Matheron 13, p.151-156)) sobre a teoria espinosana da imitação afetiva. De fato, Montag mostrou justamente que

esta teoria [...] não exclui, de modo algum, a noção de indivíduos originariamente dissociados que permanecem dissociados mesmo na sua imitação dos afetos dos outros. Com efeito, o texto de Espinosa fornece o fundamento para uma leitura segundo a qual a imitação dos afetos não seria outra coisa que um ato de projeção que requer apenas que eu imagine que o outro sinta prazer ou dor, de modo que eu imite aquilo que imagino que seja o sentimento do outro. Esta é precisamente a definição de simpatia dada por Adam Smith na primeira parte da Teoria dos Sentimentos Morais, capítulo I. Para Smith, não há atravessamento do limite que me separa dos outros; eu não posso nunca saber o que experimenta um outro homem, ou se experimenta alguma coisa. A simpatia permanece interna àquilo que Smith chama o 'espectador': este imagina aquilo que ele mesmo experimentaria ou experimentou em circunstâncias similares à do outro. Para Smith, a rigor, a simpatia não requer nem mesmo a existência do outro. É-me possível experimentar piedade com relação ao morto, dado que não há comunicação ou transferência de sentimento ou afeto através da infinita distância que me separa dos outros, mas apenas uma projeção de mim mesmo.(Montag 14, p.76)

Em outras palavras, a imitação afetiva constituiria, em um plano ontológico, aquilo que em um plano metodológico é, em Husserl, a apresentação analógica do alter 
ego: a ponte entre os indivíduos é erguida a partir da projeção de uma interioridade em modo analógico (não é por acaso que Husserl usa aqui, mesmo que com extrema cautela, o termo empatia, Einfühlung).

Todavia, a leitura do modo à luz do conceito e mônada, mesmo sendo provisória, é extremamente problemática. Tomemos, em primeiro lugar, o escólio que encerra o pequeno tratado de física da segunda parte da Ética, o qual desvincula o conceito de indivíduo corpóreo de qualquer forma de substancialidade, colocando o principium individuationis em uma determinada proporção (certa ratio) de movimento e de repouso das partes que entram no processo de sua composição e de sua regeneração na relação com o ambiente:

Vemos, assim, em que proporção um indivíduo composto pode ser afetado de muitas maneiras, conservando, apesar disso, sua natureza. Até agora, entretanto, concebemos um indivíduo que se compõe tão-somente de corpos que se distinguem entre si apenas pelo movimento e pelo repouso, pela velocidade e pela lentidão, isto é, que se compõem de corpos mais simples [ex corporibus simplicissimis componitur]. Se, agora, concebemos um outro indivíduo, composto de vários indivíduos de natureza diferente, veremos que também ele pode ser afetado de muitas outras maneiras, conservando, apesar disso, sua natureza. Pois, como cada uma de suas partes compõe-se de vários corpos, cada uma delas poderá, portanto [...], sem qualquer mudança de sua natureza, mover-se ora mais lentamente, ora mais velozmente e, como conseqüência, transmitir seus movimentos às outras partes, ora mais lentamente, ora mais velozmente. Se concebemos, além disso, um terceiro gênero de indivíduos, compostos de indivíduos do segundo gênero, veremos que também ele pode ser afetado de muitas outras maneiras, sem qualquer mudança de forma. E se continuamos assim, até o infinito, conceberemos facilmente que a natureza inteira é um só indivíduo, cujas partes, isto é, todos os corpos, variam de infinitas maneiras, sem qualquer mudança do indivíduo inteiro.(Espinosa 4, II, lema 7, esc., p.102; trad. it., p.139; trad. bras.103-105)
O escólio atraiu a atenção da crítica pelo referimento espinosano aos corpora simplicissima e à natureza entendida como indivíduo total. Na minha opinião, trata-se de Holzwege, de caminhos que não levam a lugar algum: em outras palavras, trata-se de termos-limite ou, para usar uma terminologia espinosana, de auxilia imaginationis, aos quais, realmente, não corresponde qualquer realidade ontológica. Parece-me claro que Espinosa não está dizendo que existem infinitos níveis de existência de indivíduos entre os corpos simples e a natureza entendida como indivíduo no seu conjunto, mas que existem infinitos níveis de existência de individualidades de complexidade crescente tout court, e a natureza consiste precisamente nestes infinitos níveis de complexidade, e não pode ser reduzida nem ao infinitamente pequeno nem ao infinitamente grande (a rigor, com efeito, nem os corpora simplicissima nem a natureza como totalidade podem ser entendidos como indivíduos em sentido espinosano).

A um olhar superficial, o escólio poderia remeter a alguns célebres parágrafos da Monadologia:

64. [...] cada corpo orgânico de um vivente é uma espécie de Máquina divina ou de Autômato natural, excedendo infinitamente todos os autômatos artificiais, porquanto uma máquina feita pela arte do homem não é máquina em cada uma das suas partes. Por exemplo: o dente de uma roda de latão tem partes ou fragmentos que já não são, para nós, algo artificial, e relativamente ao seu uso nada possui de característico da máquina a que a roda se destinava. As máquinas da Natureza porém, ou seja, os corpos vivos, são ainda máquinas nas suas menores partes, até ao infinito. Eis o que distingue a Natureza e a Arte, que dizer, a Arte Divina e a nossa. 65. E o Autor da Natureza pôde executar este artifício divino e infinitamente maravilhoso, por ser cada porção da matéria não só divisível até ao infinito [...], mas estar ainda atualmente subdividida sem fim, cada parte em partes, tendo cada uma delas movimento próprio. De outro modo seria impossível poder cada porção da matéria exprimir todo o universo.

66. Isto revela a existência de um mundo de criaturas, de viventes, de animais, de Enteléquias e de almas na mais ínfima porção da matéria. 
67. Cada porção da matéria pode ser concebida como um jardim cheio de plantas e como um lago cheio de peixes. Mas cada ramo de planta, cada membro de animal, cada gota de seus humores é ainda um jardim ou um lago. (Leibniz 12, §64-67, p. 618; trad. it., p. 463-464).

Entretanto, se se analisam as duas passagens com atenção, não se pode deixar de destacar que em Leibniz há uma analogia estrutural entre os diferentes níveis de individualidade (as metáforas do lago e do jardim exprimem precisamente isto), enquanto em Espinosa a complexidade do nível superior não guarda qualquer analogia estrutural com a do nível inferior: ela constitui, antes, a emergência de um grau de individualidade que não estava contida previamente nos graus de individualidade que entraram na sua composição.

A diferença aparecerá com total evidência lendo-se este parágrafo da Monadologia:

70. Assim se vê ter cada corpo vivo uma Enteléquia dominante, que no animal é a alma, mas estarem os membros deste corpo vivo cheios de outros viventes, plantas e animais, cada qual, ainda, com a sua Enteléquia ou a sua alma dominante.(Leibniz 12, §70, p.619; trad. it., p.464).

Em Leibniz, o corpo, a vida é comandada por uma hierarquia de formas cujo nível (isto é, a posição na escala hierárquica do ser) é dado de uma vez por todas, ainda que o fluxo perpétuo dos corpos torne impensável que uma alma tenha uma verdadeira e própria posse de seres viventes de ordem inferior (Leibniz 12, §71, p.619; trad. it., p.464); em Espinosa, ao contrário, a mente não é, de fato, a forma do corpo, não é a reductio ad unum da pluralidade da matéria, ela é o corpo mesmo, mas expresso segundo um atributo diferente: isto significa que as mentes devem ser pensadas segundo o mesmo modelo dos infinitos níveis de complexidade através do qual Espinosa descreveu a estrutura dos corpos, pelo menos como impõe a proposição 7 da segunda parte da Ética. O indivíduo mente-corpo, então, não é pensável como uma mônada fechada, mas como um composto de indivíduos que, por sua vez, entra na composição de indivíduos de nível superior: qualquer nível que se escolha considerar, encontrar-se-á sempre o indivíduo como momento duplamente provisório entre dois níveis de individualidade, ou seja, para usar a terminologia de Simondon, encontrar-se-á que o indivíduo é, na realidade, posterior com respeito ao processo de individuação que o constitui enquanto tal.

Para retornar ao confronto com Leibniz através do tema das relações, pode-se colocar em relevo que a teoria da harmonia preestabelecida impõe que cada determinação extrínseca seja fundada sobre uma determinação intrínseca, ou seja, que cada relação exterior seja fundada em uma propriedade da mônada, seja um estado interno da mônada (e cada estado é infinitamente complexo porque deve exprimir todo o inter-individual em nível intra-individual), em Espinosa, cada determinação intrínseca é, na realidade, fundada sobre um complexo jogo de determinações extrínsecas (o que não significa, contudo, que as determinações extrínsecas possam conter antecipadamente a determinação intrínseca), ou seja, cada propriedade de um indivíduo é produzida pelo complexo jogo de relações que constituiu sua individualidade. Neste sentido, parece-me dotada de todo o sentido a contraposição mônada/modo, lida através das lentes contemporâneas da contraposição entre intersubjetividade e transindividualidade.

\section{Paixões: não propriedades, mas relações}

Trata-se, agora, de tentar mostrar como a aplicação do modelo da transindividualidade torna possível uma leitura nova da teoria das paixões de Espinosa, entendendo estas últimas não como propriedades de uma natureza humana supra-histórica, mas como trama transindividual que constitui formas de individualidade que são, em última instância, históricas.

É verdade que em respeito ao mos geometricus da Ética e de algumas formulações de Espinosa, poder-se-ia sentir a tentação de ler as paixões na teoria espinosana como propriedades ${ }^{10}$, ou seja, como denominações intrínsecas, características da essentia intima da natureza humana tomada separadamente de todo o resto. Mas se pode realmente tomar, na ontologia espinosana, uma realidade separadamente de todo o resto? Pode-se mesmo entender de modo técnico a paixão como proprietas, ou seja, como aquilo que é proprium a uma essentia que precede as relações e as circunstâncias existenciais?

Em uma recente tradução do Tratado Político, Paolo Cristofolini propôs uma 
tradução extremamente densa de significados para uma locução freqüente na escrita de Espinosa: "passionibus obnoxius". Dever-se-ia traduzir literalmente por subjugados, submetidos, sujeitos às paixões; Cristofolini nota que "a palavra latina obnoxius contém, entretanto, o duplo significado particular daquilo que causa dano e daquilo que invade ou permeia", e então propõe, sob escolta de um modelo de tradução leopardiana de Epicteto, traduzir tal expressão por "atravessados pelas paixões". A partir desta tradução pode-se tentar pensar as paixões não como proprietates de uma natureza humana genérica, dada de uma vez por todas, mas como relações que atravessam o indivíduo, constituindo a sua dimensão social e histórica.

Seria apenas o caso de repetir que o indivíduo para Espinosa não é nem substância nem sujeito (nem ousia, nem hypokeimenon), é uma relação entre um exterior e um interior que se constituem na relação (ou seja, não existe a interioridade absoluta do cogito diante da exterioridade absoluta do mundo do qual o corpo próprio é parte). Essa relação constitui a essência do indivíduo, que nada mais é do que a sua existênciapotência; não se trata, no entanto, de uma potência dada de uma vez por todas, mas de uma potência variável, justamente porque a relação que constitui o interno e o externo é instável e não dada de uma vez por todas. Ora, as paixões não são as propriedades de uma natureza humana dada, propriedades que existem antes do encontro e que são de algum modo ativadas por este, mas são as relações constitutivas do indivíduo social: o lugar originário a partir do qual agem as paixões não é a interioridade, mas o espaço entre os indivíduos, dos quais a interioridade mesma é um efeito histórico. Claro, Espinosa define o desejo, a alegria e a tristeza os três afetos primários ${ }^{11}$ : poder-se-ia, então, entender esses afetos primários como propriedades fundamentais da essência humana, propriedades que antecipam os encontros produzidos pelas relações indivíduo-ambiente e recebem diferentes matizes com base nestes. Na realidade, se estes afetos são primários com respeito ao indivíduo, não o são se se coloca do ponto de vista da causalidade imanente, que dá lugar ao indivíduo enquanto connexio singularis, entrelaçamento singular. Em tal perspectiva, os afetos primários nada são além de elementos abstratos antes de entrar em relação; mas não apenas, pois eles não podem sequer existir em estado puro, elementos originários de cuja combinação nascem todos os outros; eles existem apenas nas infinitas metamorfoses que as relações com o exterior lhes impõem: ódio, amor, esperança (segurança / gáudio), medo (desespero / remorso), etc. E, além disso, não se pode nem mesmo falar de um afeto singular como relação transitiva a um objeto ${ }^{12}$, uma vez que, por efeito da causalidade imanente, que no âmbito do finito se mostra como nexus causarum, entrecruzamento de causas, cada afeto é sempre sobredeterminado por outros. ${ }^{13}$

Assim, as paixões não podem ser pensadas através da categoria de propriedade, da inerência de um predicado a um sujeito, mas como complexa trama de relações. Como escreve de maneira perfeita Montag,

a imaginação, que de certo modo faz a mediação entre o interno e o externo, entre o si mesmo e o outro, agindo como canal entre o meu corpo considerado como uma coisa singular e outros corpos igualmente singulares, dá ádito a uma imitação imediata que não é tanto uma duplicação do afeto de uma pessoa na outra, mas [...] uma perpetuação ou persistência de afeto sem a mediação da pessoa. O afeto, portanto, não resulta contido em mim ou nos outros, mas entre nós.(Montag 14, p.77).

Dessa forma, a trama da vida afetiva existe entre os indivíduos e os constitui enquanto tais. Isso significa que não se dá qualquer espelhamento interior do outro, da mônada do outro na minha mônada, precisamente porque o outro é aquilo do que somos entretecidos.

\section{Conclusões}

Através deste longo percurso histórico e teórico, buscou-se observar a oposição Espinosa-Leibniz segundo uma perspectiva que não se limitasse a repetir a fatigada canção hegeliana da dialética Um-Muitos, mas, antes, que procurasse desentranhar dela toda força e atualidade. O que parece ter emergido em termos de resultados filosóficos a partir desse percurso é o fato de que a retomada husserliana da monadologia em termos transcendentais se encontra diante de um definitivo malogro, o da inatingibilidade do Outro pela consciência: a intersubjetividade ou é metafísica ou nada é (e, assim, o modelo mais rigoroso de intersubjetividade vem a ser aquele leibniziano). De fato, a 
intersubjetividade transcendental introduz sub-repticiamente um conceito de harmonia metafísica sem o qual o eu e o alter não podem pertencer ao mesmo tempo, ao mesmo mundo. De que maneira o modelo da transindividualidade permite evitar esse malogro? Ele o evita justamente porque o outro não está para além da cercadura fechada do ego, mas está já e sempre no ego (e, claro, em uma tal perspectiva, a própria contraposição ego-alter nada mais é que a substantificação de uma função gramatical), o atravessa, o constitui enquanto tal como trama complexa de corpos, paixões, idéias, palavras, trama complexa de temporalidade não redutível à contemporaneidade essencial de uma comunidade. ${ }^{14}$ Como escreve Lucrécio em um esplêndido verso que me apraz pensar que tenha inspirado Espinosa:

\section{Inter se mortales mutua vivunt. ( De rer. Nat., II, 76)}

\section{Intersubjectivity and transindividuality from Leibniz and Spinoza}

Abstract: One of the greatest persistent misunderstanding around leibnizian philosophy is to think it as a sort of spinozism. Likewise, every attempt to show Leibniz and Spinoza as opposed to each other do not surpass the hegelian interpretation, according to which both philosophies are seen as antagonism between universality and individuality. Our aim is, on the contrary, to contrast one philosopher to another in respect to the matter of individuality and their relations to the XXth Century thinking: on the one hand, the husserlian intersubjectivity as the philosophical continuation of the Monadology; on the other hand, the simondnian concept of transindividuality, which upon the developments of Balibar turns the spinozian thought possible to be continued in contemporaneity. We intend to show the distance that keep both systems away one from another by means of an interpretation that do not simply repeat the old hegelian refrain.

Keywords: Spinoza, Leibniz, transindividuality, intersubjetivity.

\section{REFERÊNCIAS BIBLIOGRÁFICAS}

1. BALIBAR, E., "Prefazione”, in: Spinoza contra Leibniz, organizada por V. Morfino, Milano, Unicopli, 1994.

2. BALIBAR, E., Spinoza. Il transindividuale, trad. it. organizada por L. Di Martino - L. Pinzolo, Milano, Edizioni Ghibli, 2002.
3. CRISTIN, R., "Introduzione” a E. Husserl, Meditazioni cartesiane, Milano, Bompiani, 1994.

4. ESPINOSA, Ethica ordine geometrico demonstrata. Im Auftraf der Heidelberger Akademie der Wissenschaften herausgegeben von Carl Gebhardt. Bd.II. Heidelberg, C. Winter. (trad. it. de E. Giancotti, Roma, Editori Riuniti, 1988) [ed. bras.: Ética. Tradução de Tomaz Tadeu. Belo Horizonte: Autêntica Editora, 2007].

5. FRIEDMANN, Leibniz et Spinoza, Paris, Gallimard, 1946.

6. HEGEL, G.W.F., Vorlesungen über die Geschichte der Philosophie, in Werke in zwanzig Bänden, vol. XX, Suhrkamp Verlag, Frankfurt am Main, 1971 (trad. it. organizada por E. Codignola e G. Sanna, Vol. 3/II, La Nuova Italia, Firenze, 1945).

7. Wissenschaft der Logik (Erster Band, "Die Objective Logik", 1812/1813), in GW, Bd. 11, hrsg. von F. Hogemann und W. Jaeschke, 1978 (trad. it. organizada por A. Moni, revisada por C. Cesa, vol. II, Laterza, RomaBari, 1988).

8. HICKS, G.D., "The 'modes' of Spinoza and the 'monads' of Leibniz", Proceedings from Aristotelian Society, 24, 1918, pp. 329-362.

9. HUSSERL, E., Cartesianischen Meditationen, in H, Bd. I, hrsg. von S. Strasser, 1950 (trad. it. de F. Costa, Milano, Bompiani, 1994).

10. JACOBI, F.H., Beylagen zu den Briefen über die Lehre des Spinoza, in Werke, Bd. 4, Abt. II, hrsg. von F. Roth and F. Köppen, Leipzig, Fleischer, 1819. (trad. italiana organizada por F. Capra, revista por V. Verra, Roma-Bari, Laterza, 1969).

11. LEIBNIZ, Die philosophischen Schriften, Bd. 3. Ed. C. I. Gerhardt, 7 vols., Berlin, Halle: 1949-63; reimpressão Hildesheim, 1962.

12. ___ Monadologia, Die philosophischen Schriften, Bd. 6. Ed. C. I. Gerhardt, 7 vols., Berlin, Halle: 1949-63; reimpressão Hildesheim, 1962. (trad. it. de M. Mugnai - E. Pasini, in Scritti filosofici, vol. 3, Torino, Utet, 2000).

13. MATHERON, A., Individu et communauté chez Spinoza, Paris, Les éditions du minuit, 1988.

14. MONTAG, W., “Chi ha paura della moltitudine?”, Quaderni materialisti, 2, 2003.

15. MORFINO, V., "Il manoscritto leibniziano ad Ethicam", Quaderni materialisti, 2, 2003.

16. _ _Introduzione" a Louis Althusser, L'unica tradizione materialista: Spinoza, Milano, CUEM, 1998, p.7-35.

17. __ "Ontologia della relazione e materialismo della contingenza", 
Oltrecorrente, 6, 2002, pp. 129-144.

18. "Temporalità plurale e contingenza: l'interpretazione spinoziana di Machiavelli”, Etica e politica, vol. VI, no. 1, 2004.

19. PACI, E., Il problema della monadologia da Leibniz a Husserl. Per una concezione scientifica e umana della società, Milano, Unicopli, 1978.

20. PIRO, F., Varietas identitate compensata. Studio sulla formazione della metafisica di Leibniz, Napoli, Bibliopolis, 1990.

21. SIMONDON, G., L'individuation psychique et collective à la lumière des notions de Forme, Information, Potentiel et Métastabilité, Paris, Editions Aubier, 1989.

22. STEIN, L., Leibniz und Spinoza, Berlin, Reimer, 1890.

\section{NOTAS:}

1 Com efeito, nas Lições sobre a história da filosofia, Hegel repete quase literalmente a opinião de Leibniz: "A filosofia de Leibniz é metafísica que, em resoluto contraste com a simples substância universal de Espinosa, na qual todo determinado é apenas uma transição, coloca como fundamento a pluralidade absoluta das substâncias individuais que, seguindo o exemplo dos antigos, ele denomina mônadas, expressão já empregada pelos Pitagóricos.” (Hegel 6, p. 238-39; trad. it., p. 187). 2 Cf., p. ex., Ludwig Stein que, no seu célebre livro sobre o espinosismo de Leibniz, afirma que a teoria das mônadas constitui o pólo metafísico oposto da teoria espinosana da substância única (Cf. Stein 22, p. 21-22). 3 Cf., obviamente, G. Friedmann, op. cit., mas também as belas fichas de F. Piro (Piro 20). 4 Trata-se de um "respectivo mundo-ambiente conhecido com seu horizonte próprio de objetos não conhecidos, que estão ainda por obter, previamente antecipados com esta estrutural formal de objeto" (Husserl 9, p.102; trad. it. p.94 ). 5 É exatamente a semelhança daquele corpo - que entra no meu domínio primordial - com o meu que faz dele "um outro corpo" (Husserl 9, p.140; trad. it. p.131). 6 Em um texto de 1978, Paci, dentro de uma tentativa conjugar fenomenologia e marxismo, propõe que se interprete a harmonia intermonádica em sentido performativo: "Em Husserl [...] há a tentativa de ver e de fazer de modo que, como eu sou claro à minha vida pessoal, que vivo em primeira pessoa, assim também deveria me ser clara a vida em primeira pessoa que o outro vive. Apenas eu vivo em primeiro pessoa aquilo que me acontece, e só tu vives em primeira pessoa aquilo que te acontece, mas eu poderia identificar-me de tal maneira contigo, que poderia sentir aquilo que você sente, e você aquilo que eu sinto, e juntos poderíamos encontrar em nós um mundo e um acordo mais rico para ambos. Se isto fosse aplicado a todas as religiões e a todas as ciências, seria fornecido um vasto panorama enciclopédico, mas que não seria compilado e adquirido segundo esquemas exteriores e nocionais, mas que seria vivido em primeira pessoa por todos os homens" (Paci 19, p. 102-103). E além do mais: "Uma pessoa, nos seus relacionamentos com as outras, é portadora de todo aquele desenvolvimento que começou na natureza material, que prosseguiu na natureza animal e que culmina na natureza social, em uma visão histórica, positiva e teleológica, da humanidade, na qual todos realizam a própria personalidade em acordo com os outros, e sem destruí-los. Deste modo, a harmonia, que para Leibniz era preestabelecida desde o início do desenvolvimento, e que aqui se coloca como escopo ao final da evolução, liga-se ao problema do espaço, do tempo e da história" (Paci 19, p. 158). E ainda: “[...] se refazemos em nós mesmos o processo da comunhão e da compreensão intersubjetiva, e se eu em um mundo, junto com outros em outros mundos, conseguimos reconhecer algo que forma, por exemplo, a classe operária e a burguesia, e nós conseguimos entender por que elas estão uma contra a outra e conseguimos quebrar todos os elementos que impedem o recíproco reconhecimento entre os sujeitos, tendemos a um mundo que provavelmente não se alcançará nunca na sua perfeição, mas que é significativo para a vida das pessoas” (Paci 19, p. 160). Enfim: “[...] é uma harmonia que para Leibniz era preestabelecida por Deus, enquanto para nós é aquilo em direção ao qual devemos nos mover, é aquilo que devemos conquistar continuamente, porque sabemos que se trata de uma harmonia que vai sempre além daquilo que alcançamos e daquilo que queremos alcançar, para dar significado à vida e à história. E intencional quer dizer também que tem uma práxis, e que não é indiferente à associação e ao acordo, nem àquela sociedade comunista que é um guia e que está viva [...], porque todo o mundo tende a este tipo de comunismo como harmonia que é, justamente, o significado de todo o universo" (Paci 19, p. 167). É evidente o paralogismo de Paci na substituição do significado teorético-epitesmológico da harmonia por aquele ético-político. 7 Sobre a importância e a presença de Espinosa na obra de Althusser, cf. minha "Introduzione" a Louis Althusser, L'unica tradizione materialista: Spinoza (Morfino 16). 8 Deve-se dizer que Balibar acrescenta: "acho isso provável, mas não estou seguro de que possa ser completamente provado pelo texto da Ética" (Balibar 2, p. 139). 9 Este tipo de leitura reaparece em muitas retomadas na história da crítica. A tentativa mais sistemática é, sem dúvida, aquela de Hicks, que indica fortes analogias entre o modo e a mônada com respeito à individualidade entendida como atividade ("de fato, Leibniz tem sido amplamente utilizado para tornar explícito o que está mais ou menos implícito na Ética. [...] A atividade, então, sobre a qual Leibniz coloca muita ênfase como constituindo a essência da individualidade foi igualmente reconhecida por Espinosa; e foi, de fato, não menos fortemente enfatizada por ele”; (Hicks 8, p. 345- 
348)), aos estados de desenvolvimento das várias formas de individualidade ("apesar de Espinosa não ter desenvolvido em detalhe sua concepção dos diferentes estágios dos [seres] animados, só com muita ingenuidade não se veria que ele estava, na prática, distinguindo os estágios que Leibniz descreve" (Hicks 8, p. 351)), e enfim, à relação que liga o indivíduo finito a Deus ("Ao desenvolver sua teoria das mônadas, Leibniz estabeleceu como seu alvo resgatar a filosofia daquela destruição da existência individual que a ele parecia estar implicada na metafísica de Espinosa. Contrapondose a Espinosa, ele assumiu como sua a posição de que apenas o indivíduo enquanto tal era o verdadeiramente real. Mas se alguém escruta mais de perto a concepção de individualidade, tal como foi desenvolvida por Leibniz, terá logo razões para suspeitar que a concepção não agüentará o peso que ele gostaria de impor-lhe. A característica absolutamente essencial à individualidade, como ele a vê, é a limitação, negação, passividade. Energia ou atividade puras e ilimitadas pareciam [...] a Leibniz incompatíveis com a noção de ser real. O que quer que seja, deve ser limitado" (Hicks 8, p. 356)).

10 Lidei com tal questão em "Ontologia della relazione e materialismo della contingenza" (Morfino 17). 11 “(...) Afora esses três, não reconheço nenhum outro afeto primário. De fato, demonstrarei, no que se segue, que desses três provêm todos os outros." (Espinosa 4, III, prop. 11, esc., p. 149; trad. it., p. 181; ed. bras. p. 179). 12 A relação mesma que liga um sujeito e um objeto não tem qualquer universalidade, como sublinha o próprio Espinosa: "Homens diferentes podem ser afetados diferentemente por um só e mesmo objeto, e um só e mesmo homem pode, em momentos diferentes, ser afetado diferentemente por um só e mesmo objeto." (Espinosa 4, III, prop. 51, p. 178; trad. it., p. 208; ed. bras., p. 221). 13 Para uma detalhada análise desta sobredeterminação, cf. ainda o meu "Ontologia della relazione e materialismo della contingenza" (Morfino 17, p. 140-141). 14 Sobre a multidão como trama complexa de temporalidades, cf. o meu "Temporalità plurale e contingenza: l'interpretazione spinoziana di Machiavelli” (Morfino 18).

\section{Estamos todos malucos... O sujeito moderno e a falha geológica*}

Eduardo Grüner**

Resumo: O artigo visa questionar as posições opostas do Sujeito Pleno cartesiano e do não-sujeito pós-moderno, que pretende criticar as razões do primeiro. $\mathrm{O}$ que se omite nessa contraposição é uma corrente de auto-crítica interna à própria modernidade e que permite pensar um Terceiro Sujeito, trágico, falho, produto da violenta história que o faz nascer.

Palavras-chave: modernidade, pós-modernidade, Sujeito Pleno, sujeito trágico.

Esta mesa muito pouco redonda chama-se, segundo entendi, Filosofia e Ensaio. O conceito de ensaio, como se sabe, é uma criação francesa. Mais especificamente, de Michel de Montaigne, que foi o primeiro em usá-lo, em 1580. Talvez, justamente por isso, seja praticamente um invento argentino - não achem vocês que há na Argentina somente um "afrancesado", são muitos; ou pelo menos, existe uma certa maneira de praticar a relação entre o ensaio literário, a filosofia e a política que é uma tradição apaixonadamente argentina. Mas não se preocupem: estamos em San Juan, então não vou falar de Sarmiento. Nem tampouco, digamos, de Martinez Estrada. Nestas mesmas jornadas tem gente muito mais capacitada do que eu para falar desse verdadeiro invento nacional que é o ensaio filosófico-político argentino. Limito-me a constatar, isso sim, que o ensaio filosófico argentino sempre teve clareza sobre seu irrenunciável caráter político. Sempre teve clareza, para parafrasear um clássico, de que a filosofia é política concentrada no pensamento e no discurso. Mas, repito, não vou falar disso. Vou falar um pouquinho, só para começar, do criador de nosso conceito, Michel de Montaigne.

Não sei se se extraíram as conclusões filosóficas suficientes do fato de que Montaigne fora um dos primeiros e, certamente, dos mais virulentos, críticos da

* Palestra apresentada no Congresso Internacional de Filosofia que aconteceu em San Juan, Argentina, em Julho de 2007. Tradução de Mariana de Gainza.

** Professor Titular de Antropologia da Arte, na Faculdade de Filosofia e Letras (Universidade de Buenos Aires) e de Teoria Política na Faculdade de Ciências Sociais (Universidades Buenos Aires). 